\title{
On the Budding Period of Chinese Original Children's Picture Books
}

\author{
Luyao Ma \\ Journal Editorial Department, Sichuan University of Arts and Science, Dazhou, China \\ Email:2867195667@qq.com
}

How to cite this paper: Ma, L.Y. (2018) On the Budding Period of Chinese Original Children's Picture Books. Open Journal of Social Sciences, 6, 307-317.

https://doi.org/10.4236/jss.2018.69021

Received: September 13, 2018

Accepted: September 23, 2018

Published: September 26, 2018

Copyright $\odot 2018$ by author and Scientific Research Publishing Inc. This work is licensed under the Creative Commons Attribution International License (CC BY 4.0).

http://creativecommons.org/licenses/by/4.0/

\begin{abstract}
The emergence of the first set of original children's picture books of modern significance in China is not accidental or sudden. Instead, it has appeared after a long period of exploration. This paper traces the origin of Chinese original children's picture books in the ordinate of history and sorts out the development history of Chinese original children's picture books in its infancy, hoping to enlighten the development and research of children's picture books at present.
\end{abstract}

\section{Keywords}

Chinese Children's Picture Books, Picture-Text Relationship, Image Narration, Budding Period

\section{Introduction}

Picture books are not only a special kind literary works but also an important educational resource. They are internationally recognized as being the most suitable books for children to read. Tadashi Matsui, known as the father of modern picture books in Japan, defines picture books as the art of combining language and pictures in a way of re-creation and visualizing as the material form of books, without losing its characteristics [1]. Peng Yi, the author of Chinese children's literature points out that picture books are an art in which pictures and words interweave and interact with each other on different levels to tell stories. Pictures are no longer the appendages of words. Instead, they are the key to the life of picture books [2]. Hao Guangcai holds the view that a picture book is probably a book, using a set of pictures to express a story, or a theme like a story [3]. Picture books in this paper are a form of books that focuses on pictures with a small number of words. They tell stories, convey knowledge and construct values through a coherent and logical set of pictures and words. From 
the above definitions, we can see that picture books have the following characteristic: the relationship between the picture and the text is "the picture $\mathrm{X}$ the text", that is to say, the picture is the main means of narration, and the text bears the function of hinting and guiding the picture. There should be continuity and narration between pictures. They embody artistic skills, possessing the physical properties of "books" (including size, shape, thickness, weight, paper, etc.).

At present, the researches on children's picture books in Chinese academic circles mainly focus on the educational value of picture books, parent-child reading, the teaching research on picture books, the application of English picture books, the development and publication of picture books, and so on, but less attention is paid to Chinese original children's picture books. Scholars in China such as Pan Mingge [4], Zhang Lijie [5] and Yang Hailian [6] have ever conducted researches on the development routes or innovative development dimensions of Chinese original Children's picture books. Wu Xiaoyue [7], Yang Dan [8] and Dai Lu [9] have conducted researches on the current situations and countermeasures of Chinese original children's picture book publication. However, so far, few scholars besides Zhang Mei have ever focused on the development of Chinese original picture books or sorted out its development process systematically [10]. Therefore, this paper attempts to clarify the history of the development of Chinese original children's picture books, in the hope of enlightening the development and research of picture books in China.

\section{Diary Story: The First Set of Illustrated Children's Reading Materials in China}

Although there was no such saying as "picture books" in ancient China, there was always a tradition of image narration. Zheng Qiao of the Southern Song Dynasty in ancient China, devoted a special discussion to the value of the picture in a chapter called The Outline of Pictures of his work Tongzhi, in which there was an incisive exposition on the tradition of "having pictures on the left and history on the right" in China [11]. In his work, Zheng Qiao highly appraised the value of images in narration and advocated the combination of texts and pictures. As for children's books, China's preliminary learning reading materials appeared much earlier in a large number. But it wasn't until the Yuan Dynasty that the illustrated preliminary learning reading material, Diary Story (Figure 1 \& Figure 2), appeared. The book contains 300 children's stories, mostly small stories that inspire children's wisdom, 168 of which have illustrations associated with them. After preliminary learning reading materials like Diary Story were produced in the Yuan Dynasty, many of them were reproduced in the Ming and Qing dynasties, but there were not many original children's reading materials with both pictures and texts.

In the late Ming Dynasty, the work called Mengyangtu Theory made a corresponding picture for each story, but the selected stories focused on promoting ethical ideas, which was not in line with children's reading interests. Until the late Qing Dynasty, none of the books for preliminary learning with pictures in 


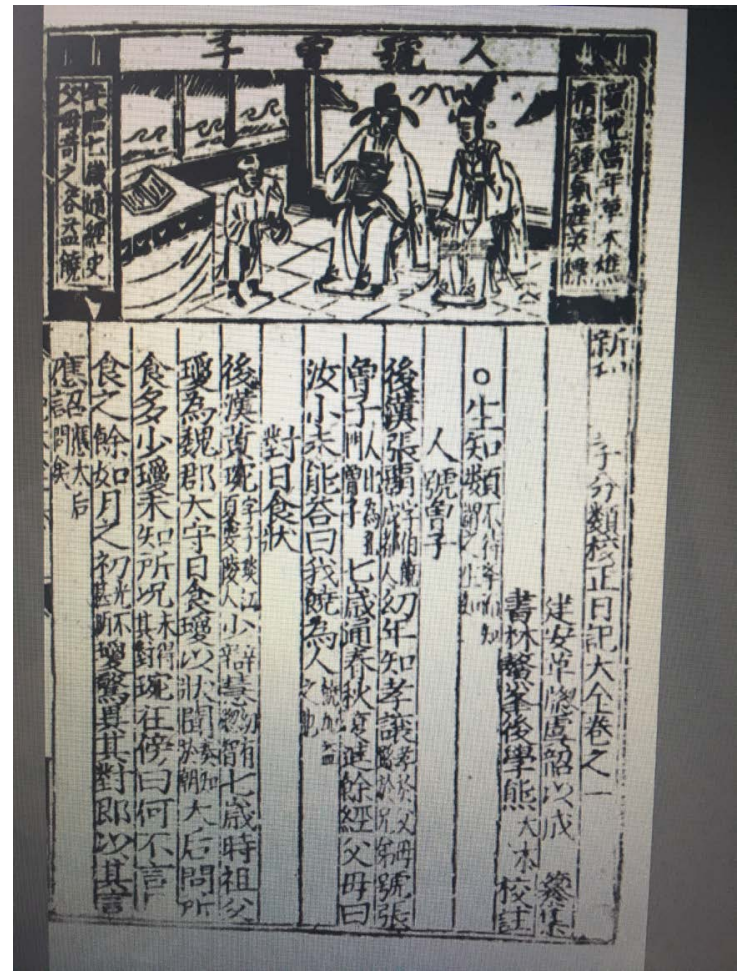

Figure 1. Diary story.

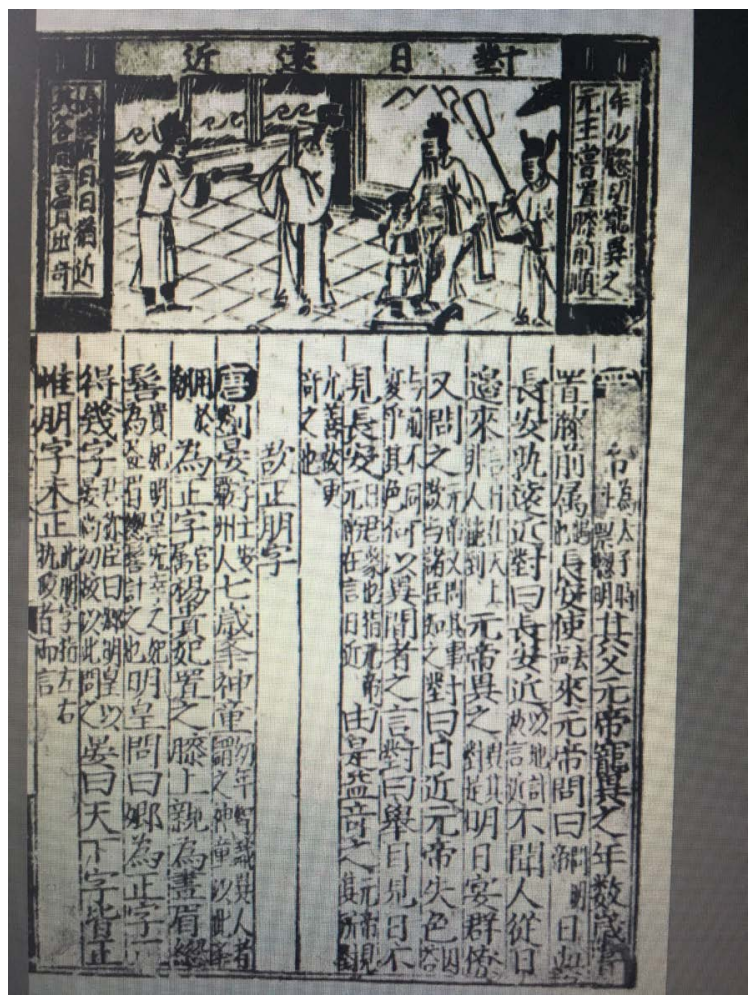

Figure 2. Diary story.

China had exceeded the program set by the Diary Story. These children's books were still mainly characters. Although the pictures were related to the corres- 
ponding characters, they were all single pictures. The lack of connection between pictures resulted in its inability to narrate with pictures to achieve the later narrative effect of continuous pictures. At the same time, the artistry of the picture was not enough. The technique and style of the pictures were not considered enough, and the engraving of the details of the pictures was missing. Pictures, as a whole, appeared to be stylized and rigid, and did not combine children's psychology and aesthetics to create pictures. Moreover, these children's picture books seemed to have been written and expressed mainly for adults, without the humorous and lively language style that suits children's language habits. In general, before the late Qing Dynasty, in children's books in China, words were the center of narration, and images were only embellishment and supplement.

\section{From Children's Monthly Magazine to Children's Education Pictures: New Practice of Children's Picture Books in Late Qing Dynasty}

In the late Qing Dynasty, missionaries brought the tradition of the western illustration children's reading materials and the advanced printing technology to China, and the children's reading materials in China began to change. The typical representative of this period was Monthly Children's Magazine founded by American missionary Dr. J. G. Kerr in Guangzhou in 1874. In 1875, John M. W. Farnham moved it to Shanghai for publication. The final edition came out in 1916 and the publication lasted 40 years from beginning to end. Like the name of the newspaper, the magazine had children as its reading audience and educating children as its running purpose. Therefore, the magazine gave priority to the understanding of things and principles in the content, which accorded with children's cognitive laws. In the form, the characters were in the language style that was more familiar to children, accompanied by vivid pictures. The use of pictures in Monthly Children's Magazine was not limited to pictures and texts. Pictures complemented words, but pictures appeared to be the protagonists of the narration. For example, when introducing the advanced technology and products of the Western world, all of them were accompanied by pictures. The knowledge was completely new to most Chinese people at that time, and it could not be fully described and understood by words alone. At this point, the pictures played a leading role in the narration, and the words were attached and supplemented, but this phenomenon was less perceived in the magazine.

The illustrations of Children's Monthly Magazine mostly used the western realistic technique and adopted the advanced copper engraving printing. Most of the illustrations were very artistic. The spread of the Children's monthly Magazine played a great role in the reconstruction of Chinese children's viewpoints in the late Qing Dynasty, and its practice of picture-text relations played a good role in demonstrating the flourishing Chinese picture books for children. If the function of the pictures in Monthly Children's Magazine was mainly concentrated on the "illustrations", then John M. W. Farnham, who also ran for the 
general publication of New Picture Newspaper, further enhanced the value of the pictures and made them have independent narration value. It pioneered the use of multiple paintings to tell a complete story, such as the use of six paintings in the fifth volume of New Picture Newspaper to tell a story of "falling into the water by car", with very few texts, while The Picture of a Flea Disturbing People tells a story in twelve pictures, with no words at all [12]. There were many examples of this kind in New Picture Newspaper. These practices have completed a great leap in the history of Chinese image narration and established the independence of image in narrative practice. Although New Picture Newspaper is not a reading material for children, it establishes the status of the image and its method of using the image, which lays the foundation for the appearance of children's picture books as children's reading form.

Under the influence of Westerners such as John M. W. Farnham, some Chinese people began to run children's publications with pictures and texts in the late Qing Dynasty. Journal of Preliminary Learning, founded in Shanghai in 1897 by the Preliminary Learning Trade Union, was the earliest children's journal founded by the Chinese themselves. The journal was arranged in the form of pictures above and texts below, which mainly focused on texts with images as a supplement. The establishment of children's picture books with Journal of Preliminary Learning in modern China mainly focuses on two points: The first point is the use of lithography technology, so that the pictures presented by the paper get rid of the rigidity of the traditional engraving printings, so that it can express the details of things more vividly and lifelike. Second, several pictures are used to express a narrative theme. For example, in the second volume the story of Mencius's Mother educating Mencius was matched the two pictures of "Three Shifts for choosing neighbors" (Figure 3) and "breaking the loom to show her child that the learning effort should not be interrupted" (Figure 4) [13]. The relationship between pictures and texts in Journal of Preliminary Learning is still dominated by texts, and pictures still have the nature of illustrations. The narrative position of pictures has not reached the height of Children's Monthly Magazine. But it is the great progress of modern Chinese in children's picture books. Journal of Preliminary Learning still uses classical Chinese to express the content, whose language style does not take into account the needs of children and is prone to be serious. Enlightenment Pictorial adopts the vernacular, which is popular with children and easy to understand, which deals well with the relationship between pictures and characters in children's picture books, and makes a better combination of clear and concise text descriptions and vivid pictures. This practice of Enlightenment Pictorial has also laid a good foundation for Chinese modern children's picture books in dealing with the relationship between words and pictures.

Because of the practice and dissemination of the above children's newspapers and periodicals, people fully realize the status of pictures in children's books. During this period, children's textbooks published by publishing institutions 


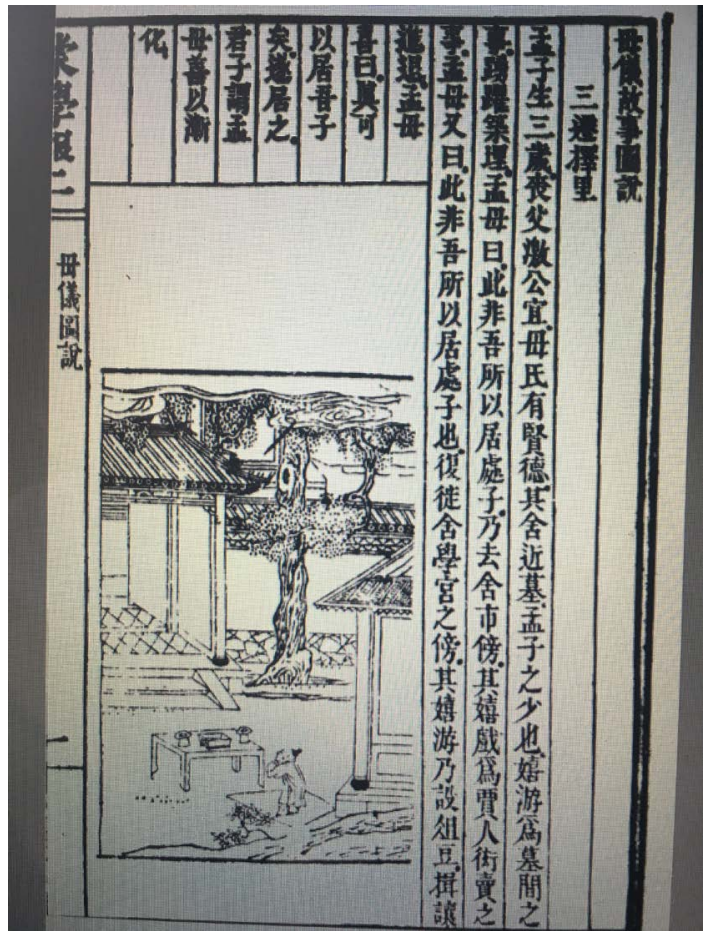

Figure 3. Three Shifts for choosing neighbors.

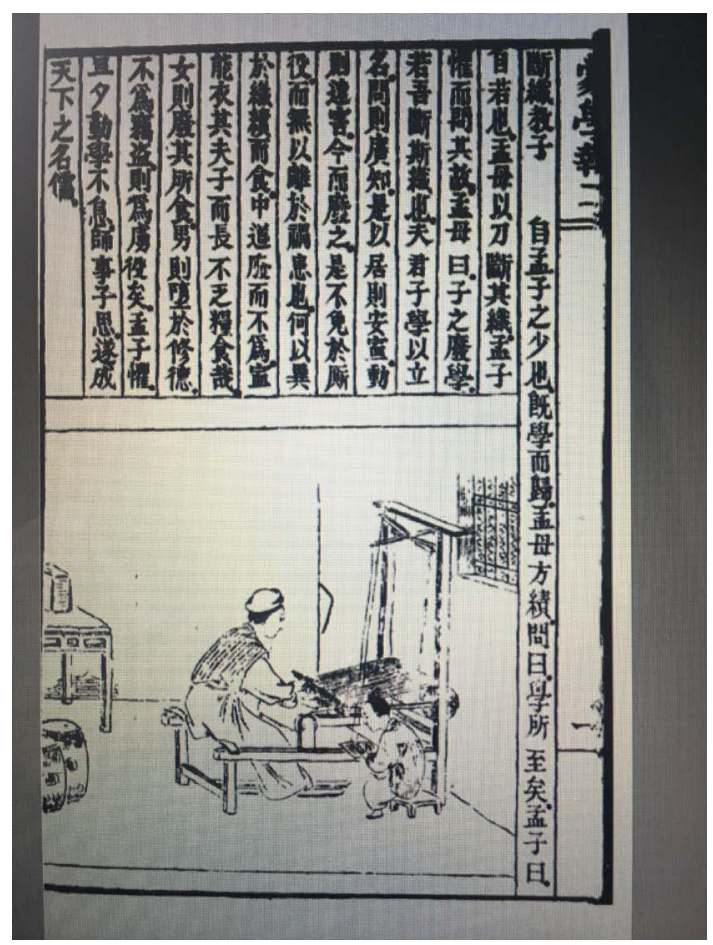

Figure 4. Breaking the loom to show her child that the learning effort should not be interrupted.

such as The Commercial Press and The Chinese Book Company were also affected by this trend, with exquisite pictures attached to each subject textbook. 102 volumes of Sun Yuxiu's picture book series, Fairy Tales, paid much attention 
to the role of pictures. In 1909, the Commercial Press founded "Children Education paintings", which aimed at primary age children and focused on image narration.

\section{Children's World: The Establishment of Picture Story as an Independent Style}

The preparation of children's concept and the publication practice of children's books have prepared for the emergence of picture stories, a new style of children's books. In China, the earliest practice of taking "Picture Story" as a conscious style was done by Zheng Zhenduo, who founded the magazine Children's World in 1922 in Shanghai Commercial Press. Children's World takes the middle and senior primary school students as the main reading objects. In volumes 1 - 9, Zheng Zhenduo created the "Picture Story" column to publish a style dominated by continuous image narration. The first picture story published in this column is Zheng Zhenduo's Adventure of the Chicken, which shows a chicken's adventure with twelve consecutive pictures and simple words [14]. In typesetting, Adventures of the Chicken changes the pattern below: text and picture are no longer formally separated, but text is flexibly placed in the picture according to the content of the picture. This form of image-text relation opens up the form of text-image in children's drawings. The magazine Children's World has the greatest impact on Chinese children's picture books by means of a serial picture story Hippopotamus Kindergarten signed by Zheng Zhendo and its sequel as well as Mrs. Bear's Kindergarten (Figures 5-7) signed by Shouyi.

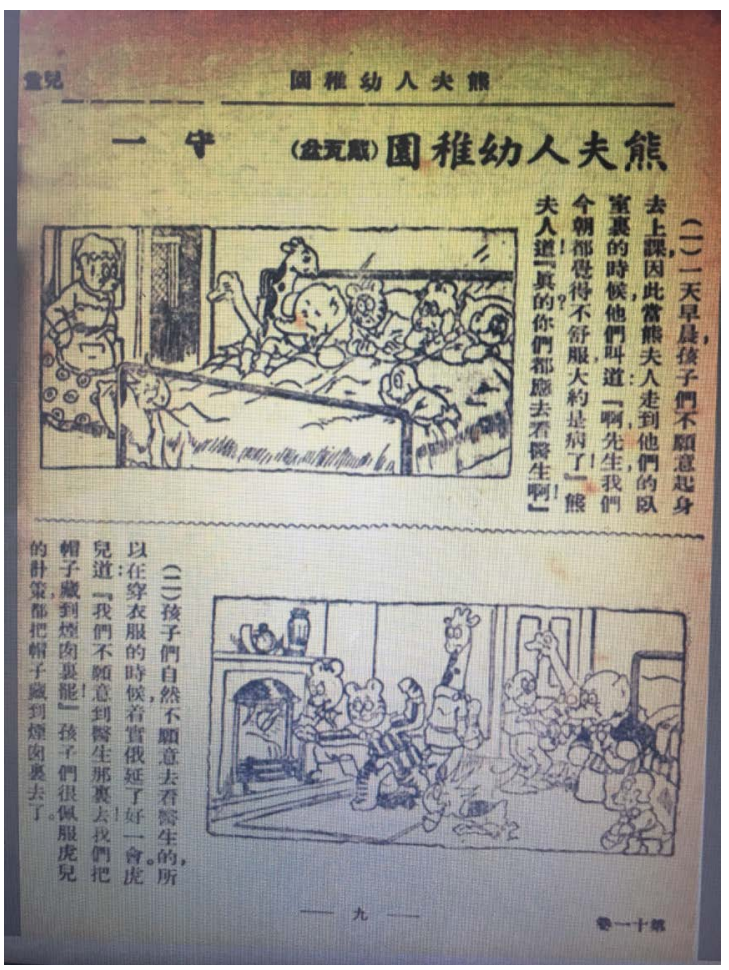

Figure 5. Mrs. Bear's kindergarten. 


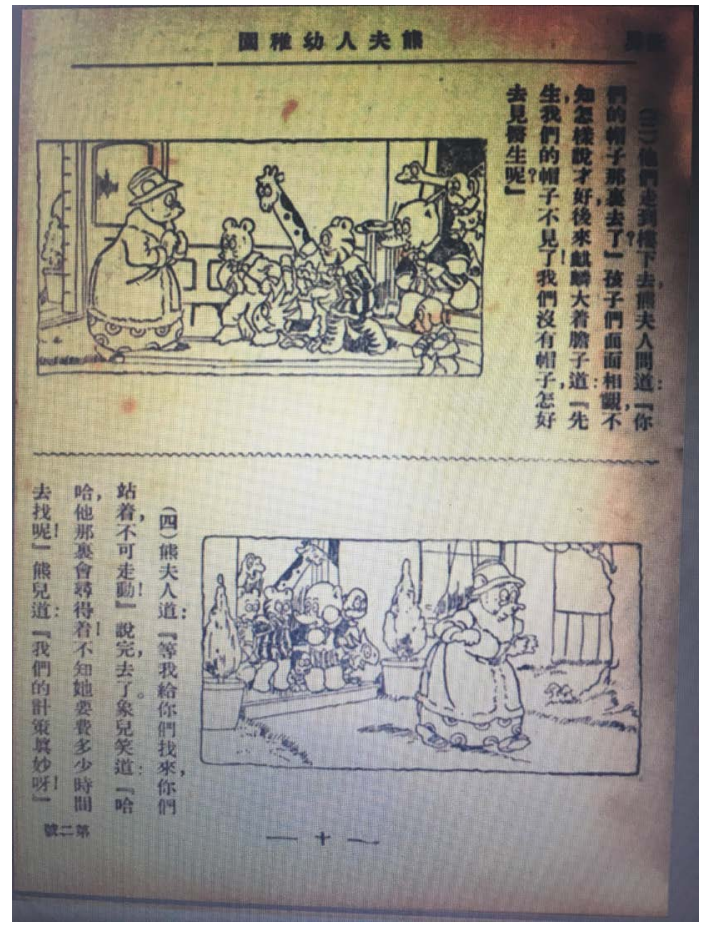

Figure 6. Mrs. Bear's kindergarten.

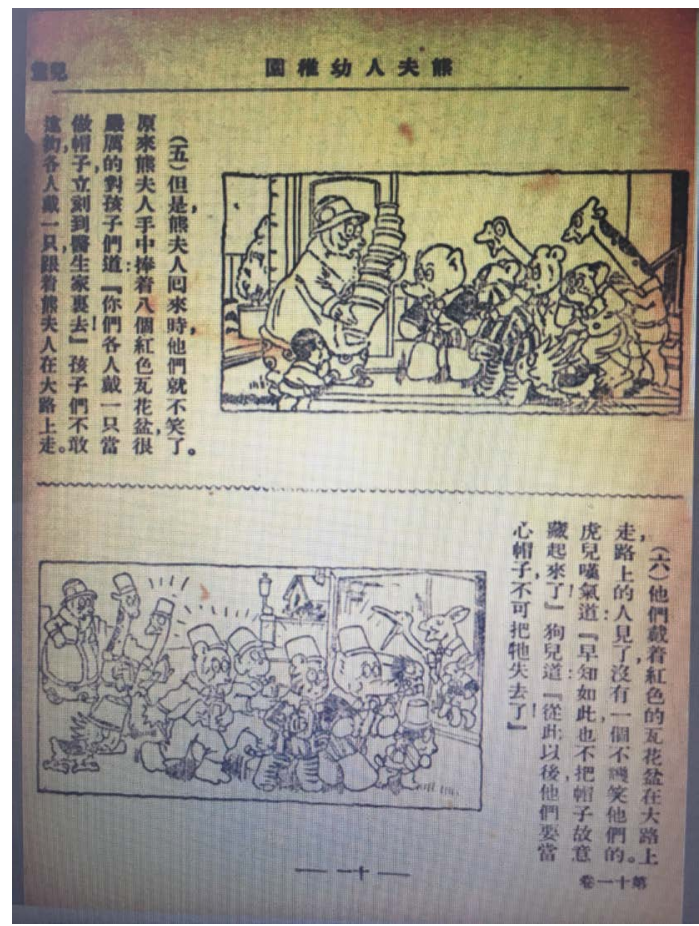

Figure 7. Mrs. Bear's kindergarten.

Hippopotamus Kindergarten was published in Children's World in issues $3-12$ of volume 4 . The story took place in the background of the kindergarten run by Mrs. Hippopotamus and was about the interesting life stories of the tiger, monkey, pig, elephant, chicken, crocodile, parrot, etc. in the school. The whole story 
is composed of poets and little stories such as fishing, the Monkey buying Fruit, Toy Store, Wild Tour, Painters, Coming up and down the Mountain, Calling for a Doctor, Hide-and-seek, Christmas Eve and A Disaster without mischief. After the publication of "Hippopotamus Kindergarten", Shouyi made a sequel named Mrs. Bear's Kindergarten, which was published in Children's World from issue 1, volume 11 in 1924 to Volume 25 in 1931, with a series of more than 300 issues and a very far-reaching impact. Chen Bochui, Guo Feng and other later writers of children's literature were deeply influenced by Mrs. Bear.

Hippopotamus Kindergarten and its sequel, Mrs. Bear's Kindergarten, are mainly pictorial continuous narration, which plays a supplementary and indicative role. The relationship between characters and pictures has already possessed the characteristics of modern children's picture books. In painting much attention was paid to techniques and style, emphasizing the fine pictures and stressing on the details of the picture. The background of the story is set up as a scene of children's daily life. The theme is the daily events of children in kindergartens, depicting the images of tigers, monkeys, pigs, chickens and other small animals that children like, and incorporating education such as knowledge, etiquette and standardization into the story. The written language adopts the spoken language which children likes and conforms to the children's language styles and the language customs. The whole series of kindergarten stories are not written or illustrated, but are discovered and supplemented by observation, reflection and imagination. These features give kindergarten series of picture stories the main essential features of modern children's picture books. It can be said that Hippopotamus Kindergarten and its sequel, Mrs. Bear's Kindergarten, have really established the foundation of Chinese modern children's picture books and made final preparations for the emergence of Chinese modern children's picture books. However, since the kindergarten series were attached to the magazine Children's World, they do not yet have the carrier form of books in the concept of picture books. At the same time, in dealing with the relationship between texts and pictures, texts and pictures sometimes overlap and that needs to be strengthened. Although kindergarten series picture stories are not the first picture books in modern China, its status in the history of Chinese modern children's picture books can not be ignored.

\section{Conclusions}

The emergence of modern children's picture books in China was not accidental or sudden. Instead, it has gone through a long preparatory process. The development process of Chinese original children's picture book in its infancy is essentially a process of its getting closer and closer to the picture books in the modern sense. In this long period of development, the following features have emerged: 1) the relationship between pictures and characters in picture books has gradually evolved from words as the main character to pictures as the secondary character; 2) the language of picture books has evolved from adult expression to 
children's oral expression; 3) pictures in the picture books have experienced such a transformation as a single picture, several independent pictures and many pictures connected with each other. Through continuous practical preparation of Diary Story to Children's World, the Commercial Press published what is considered to be the first set of original children's picture books of modern significance in China in 1934.

Through the above-mentioned carding, this paper clarifies the development of Chinese picture books in its budding period. Although there are still some gaps between the Chinese picture books in the budding period and those in the modern sense, this is in line with the law of the development of things themselves and the objective laws of people's understanding of things. At the same time, it also gives some enlightenment to the current picture book development: firstly, the development of picture books should establish a scientific ontological view of children; secondly, special attention should be paid to the relationship pictures and texts in picture books; thirdly, the theme of stories in picture books should be as close as possible to the daily life of children and restore it; fourthly, picture books should pay attention to the artistic skills of pictures and images; lastly, the language of picture books should be used in keeping with the language characteristics of children.

This paper's carding of Chinese early childhood picture books belongs to rough line carding, which is also the deficiency of this paper. In the future, the study of early childhood picture books in China can also be explored from the following aspects: Diary Story and the background of the children's reading materials; the inheritance and development of other pictorial children's books in the Ming Dynasty to Diary Story, the relationship between all kinds of children's reading materials of picture in the late Qing Dynasty, Chinese children's reading traditions and western children's reading material traditions, and so on.

\section{Conflicts of Interest}

The authors declare no conflicts of interest regarding the publication of this paper.

\section{References}

[1] Matsui, T. (1997) My Theory on Picture Books. Hunan Children's Publishing House, Changsha.

[2] Peng, Y. (2007) Picture Books: Reading and Classics. 21 Century Press, Nanchang.

[3] Hao, G.C. (2016) How Good Is a Good Picture Book. Beijing New Star Press, Beijing.

[4] Pan, M.G. (2016) An Analysis of the Development path of Chinese original Children's Picture Books. China Publishing Journal, 9, 32-35.

[5] Zhang, L.J. (2017) An Analysis of the Innovative Ways of Development of Chinese Original Children's Picture Books. Art Education Research, 10, 34-35.

[6] Yang, H.L. (2018) An Analysis of the Development path of Chinese Original Children's Picture Books. News Research Guide, 1, 218. 
[7] Wu, X.Y. (2014) A Study on the Current Situation and Countermeasures of the Publication of Original Chinese Children's Picture Books. Hunan Normal University, Changsha.

[8] Yang, D. (2016) A Study on the Present Situation and Development Strategy of Publication of Chinese Original Children's Pictures. Hebei University, Baoding.

[9] Dai, L. (2017) Main Problems and Countermeasures in the Development of Chinese Original Picture Books. Art Education Research, 8, 55-57.

[10] Zhang, M. (2011) Another Kind of Modernity Demand: Image Narration in 1875-1937 Children's Literature. Shandong Normal University, Jinan.

[11] Zheng, Q. (2000) Tong Zhi. Zhonghua Book Company, Beijing.

[12] Yi, M. (1881) The Picture of a Flea Disturbing People. New Picture Newspaper, 10, 98.

[13] Yi, M. (1897) Pictorial Account of Maternal Story. Journal of Preliminary Learning, $2,13$.

[14] Zheng, Z.D. (1922) The Adventure of the Chicken. Children's World, 9, 22. 